\title{
Product Development Benchmarking Versus Customer Focus in Applications of Quality Function Deployment
}

\author{
JOHN E. ETTLIE \\ The Michigan Business School, University of Michigan, Ann Arbor, Mich. 48109-1234 \\ MICHAEL D. JOHNSON \\ The Michigan Business School, University of Michigan, Ann Arbor, Mich. 48109-1234
}

Key words: customer focus, process improvement, benchmarking, QFD

\begin{abstract}
The study explores the tradeoff between efforts to benchmark on product-development practices and be customer focused in the implementation of a quality-improvement method. The results of a survey of thirty-three firms' experience with quality function deployment (QFD) reveal that benchmarking on how competitors, peers, or role models develop products facilitates process improvement but hinders customer focus. Smaller firms are also shown to gain more customer focus and process-improvement benefits from QFD than larger firms.
\end{abstract}

Although various perspectives exist on how to improve product and service quality and customer satisfaction, two common themes emerge. Firms must (1) focus on an accurate set of customer specifications and (2) have a production and service or maintenance process that achieves conformance to those specifications. While quality-improvement methods and programs strive to accomplish both objectives, in practice, one's path to quality improvement may be dependent on one's orientation. Firms that focus on customers look more externally to the "voice of the customer" (VOC) as the key to producing high-quality products (Griffin and Hauser, 1993). In contrast, firms that emphasize internal process changes are more likely to focus on whether or not their processes are competitive and efficient (Crosby, 1979).

This study explores a potential tradeoff that firms may encounter when they strive to be more customer focused and improve their processes. Process improvement is often accomplished by benchmarking on competitors' product-development methods. In this context, benchmarking involves making visits to firms with "quality" reputations to gauge their practices or reverse engineering their products to learn what competitors or peers are doing, see how they are doing it, and understand what is possible (Camp, 1989). Yet benchmarking efforts may come at the expense of customer focus. We examine this tradeoff in applications of quality function deployment (QFD), a method designed to improve both customer focus and internal processes. A study of thirty-three firms' experience with QFD 
is reported. The results support the proposed tradeoff and show that smaller firms gain greater customer focus and process improvement using QFD than do larger firms.

\section{Customer focus, process improvement, and QFD}

Quality function deployment uses the "house of quality" approach to documenting customer needs and wants and connecting these to their means of accomplishment (Hauser and Clausing, 1988). QFD starts with an input list of objectives or root customer needs for the target market or segment for which the product is being developed - such as a smoother ride in an automobile. The "house of quality" then translates these objectives into engineering characteristics and targets. In subsequent "houses," engineering targets are translated into design requirements, design requirements are translated into desired parts characteristics, and parts characteristics are translated into key production-process operations.

QFD aspires to accomplish two primary objectives. First, by explicitly incorporating the VOC into the product-development process, an organization's efforts maintain an external focus on customers. Second, by improving coordination, it helps improve processes and conformance to product specifications. Although research on QFD is scarce, an important exception is recent work by Griffin and Hauser (Griffin, 1989, 1992; Griffin and Hauser, 1992, 1993). Griffin and Hauser (1992) found that QFD enhanced communication within a product-development team. In another study, Griffin (1992) found that while QFD yielded only minor short-term performance benefits, it provided definite strategic benefits within the product-development process. Overall, while the popularity of QFD is growing, many of its benefits and the tradeoffs inherent in its use remain unclear.

\subsection{Customers versus competitors: the QFD experience}

Because QFD strives to improve both processes and customer focus, it provides an excellent context for studying an important quality-improvement tradeoff. Intelligence gathering for quality improvement includes input from both customers and competitors or peers. QFD presumes that the VOC input to the first house is an accurate representation of customer needs. The development team also requires an understanding of best-practice quality-improvement tools, processes, and procedures - such as Taguchi methods, Pugh analysis, and statistical process control (Ettlie and Stoll, 1990). While sound market research provides the former, benchmarking on product-development methods provides the latter.

However, firms that actively benchmark on product-development methods and processes may have difficulty staying customer focused. One reason is that the team may have a prevailing perspective or conform to a particular cultural norm that guides its actions (Fiske and Taylor, 1984). Followers of Crosby (1979) 
strongly believe that quality is free. That is, by emphasizing internal process changes in order to do things correctly the first time and to become "best in class" at these processes, costs will decrease and satisfaction will increase. Yet these firms may be so focused on competitors or peers and best practices that customer focus actually suffers. A second reason that benchmarking may hurt customer focus is that development teams have a limited capacity for improvement; companies may try to do too much too soon and make things worse in the process (Port and Smith, 1992).

\subsection{Predictions}

Our interest here is in the tradeoffs inherent in the use of methods such as QFD rather than the market success or failure of the products and services involved. We examine the effects of two exogenous factors - the use of benchmarking and the size of the organization - on the two primary goals that QFD seeks to accomplish - customer focus and process improvement. The degree to which these two goals are realized should directly affect whether or not a product-development team perceives its efforts in implementing QFD to be a failure or success. This suggests a conceptual model in which benchmarking and firm size directly affect perceptions of QFD-based customer focus and process improvement, which, in turn, affect of the incidence of perceived QFD failures. We operationalize QFDbased customer focus by whether or not firms recognized the need for good market input data (positive indicator) and the degree to which the VOC got lost in the process (negative indicator) when implementing the method. Process improvement is operationalized by the degree to which QFD allowed the teams to incorporate production requirements earlier and shorten lead time (positive indicators). We expect that firms that gain more customer focus using QFD should have a lower incidence of failures. Similarly, firms that gain more process improvement using QFD should have a lower incidence of failures.

We propose a tradeoff involving benchmarking, customer focus, and process improvement. Benchmarking should provide an understanding of the tools and techniques necessary to improve processes using QFD and make QFD work. Thus firms that benchmark should gain more process improvement using QFD than those that do not. However, due to the particular emphasis, "quality perspective," or limited capacity of product-development teams, this focus on the competition should have a negative effect on QFD-based customer focus.

A second exogenous variable of interest is the size of the organization involved. Deshpande and Zaltman (1981) argue that the greater the "interdepartmental connectedness" in an organization, the greater the market orientation; more departmentalized organizations have a harder time generating and disseminating market information. Gaining customer focus and process improvements via QFD should be more difficult in larger organizations with well-defined departmental walls and rigid organizational structures. Thus we expect a negative effect of firm size on 
QFD-based customer focus and QFD-based process improvement. An alternative prediction is that because larger firms have more resources and may be more able to adopt benchmarking practices (Damanpour, 1991), they actually have more to gain from using QFD than do smaller firms.

The conceptual model that summarizes the proposed relationships is presented in Figure 1. For brevity, the figure also presents our empirical results. Our model is exploratory. We are not interested in testing the model itself against other model specifications; our interest is in testing our predictions and explaining the incidence of QFD failures.

\section{Empirical study and results}

In cooperation with the American Supplier Institute, our survey of QFD usage and new-product development was announced at the Fourth Annual Symposium on Quality Function Deployment held in Novi, Michigan, June 15-16, 1992. A two-page questionnaire with a self-addressed and stamped return envelope was provided with registration material, and a drop box for questionnaires was provided on the registration desk. Only companies that had actually adopted QFD were eligible for the study. A dozen questionnaires were returned in this manner. After three weeks only three more questionnaires were returned. Therefore, a follow-up mailing to conference attendees was conducted, which brought the total of completed questionnaires to forty-six by August 1992. It is impossible to determine the total population of QFD users who attended the symposium, but ASI conference officials estimated that of the 237 attendees, about half (118) had QFD experience and training and could respond to the survey. The number of QFD cases actually presented at the conference was thirty-seven. Therefore, a conservative estimate is that the ultimate response rate was 39 percent ( 46 out of 118 ).

The respondents were key informants from the participating firms, which included 16 ( 35 percent) product managers, 8 ( 17 percent) engineers, 3 ( 7 percent) technical personnel, 2 ( 4 percent) general managers, and 1 ( 2 percent) consultant. The remaining 16 respondents did not list their job titles. The majority of reporting firms fell into well-known manufacturing industrial categories, 12 or 26 percent in SIC code 36 (electrical machinery), 8 or 17 percent in SIC 28 (chemical companies), 5 or 11 percent in SIC 35 (nonelectrical machinery), and 4 each (9 percent) in SICs 37 (transportation) and 38 (instruments). The other 13 firms in the sample represented the food, wood products, rubber, metal, fabrication, and consulting sectors. The majority of these firms ( 32 or 69 percent) were publicly held, and the average number of employees across all the firms was 24,955 (ranging from 2 to over 100,000$)$. These firms had average annual revenues of almost $\$ 5.2$ billion (ranging from $\$ 200,000$ to $\$ 40$ billion).

The survey contained three major sections of questions. The first section contained questions on company background (ownership, number of employees, revenues, and so on). The second section contained a number of questions related to 
the firms' product-development practices (such as, "Does the firm have a program for upgrading the product development process?," "Does the firm benchmark on design and product-development methods?," Who do they benchmark on?"). The third section contained questions relating to the firms' experience with QFD, including the key challenges they faced in making QFD work, the benefits QFD provides, and the number of failures encountered.

The ultimate endogenous variable in our model is the incidence of QFD failures. To measure this, respondents were asked to report, anonymously and confidentially, the number of known QFD failures in their organization. Only 21 of the 46 firms reported a value. We felt that a primary reason for the lack of responses was that firms with no failures left the question blank. In follow-up telephone interviews we were able to contact the key respondents for 13 of the 25 nonreporting firms by phone, and, as expected, 12 of these firms reported no failures (the other reported two failures). These 13 missing cases were added to the data. One firm reported 8 QFD failures, three more than any other firm, and this firm's responses significantly increased the variance in several variable relationships. This case (a publicly owned firm with 80,000 employees and $\$ 12$ billion in revenues, which does not benchmark on development methods) was removed from the data as an outlier (Andrews et al., 1972). Our model estimation focused on the remaining 33 firms that provided information on QFD failures. At the same time, we examined the sensitivity of our results to the inclusion of missing case values and other potential outliers.

\subsection{Variable measures and analysis}

Process benchmarking is measured categorically by whether or not firms indicated that they "benchmark" (measure $B_{1}$ ). Specifically, the key informants were asked, "Do you BENCHMARK (e.g., make visits to other firms and gauge their practices because of their known reputation or through reverse engineering) in design and the product-development process?" A total of 24 out of the 33 firms indicated that they benchmark (72 percent). Firm size is measured reflectively using two continuous variables - the firm's total revenues in the last year $\left(S_{1}\right)$ and the number of year-round, full-time employees in the firm $\left(S_{2}\right)$.

As mentioned, QFD-based customer focus is operationalized using two measures. The first is whether or not the development teams explicitly recognized the need for good market research input (VOC) when attempting to make QFD work $\left(C_{1}\right)$. Development projects that fail to recognize the need for proper market input data start off on the wrong foot. The likelihood of misinterpretation and mistakes in translation increase when the need for good information goes undetected. As a result, the ability of the method to increase customer focus is compromised, and overall the method is more likely to fail. In contrast, firms that recognize the need for good market input data should gain greater customer focus and encounter fewer failures in their attempts to apply the method. A total of 9 of the 33 firms 
explicitly recognized the need for good market input data when they were implementing QFD. Two other measures were included in the initial analyses. These were seven-point Likert scale ratings of the degree to which the respondent disagreed with two statements - "The voice of the customer got lost in the QFD process" and "In QFD, the voice of the customer became too complex or fragmented." The latter of these measures had a low positive loading on QFD-based customer focus so that, in the final analyses, we used the "lost in the process" rating as our second measure of customer focus $\left(C_{2}\right)$.

QFD-based process improvement is operationalized using two seven-point Likert rating scale measures. These are the degree to which the respondent agreed with two statements - "QFD helps incorporate production process requirements early" and "QFD is a way to shorten lead time" $\left(P_{1}\right.$ and $\left.P_{2}\right)$. Both of these measures are key indicators of process improvement in the development process (Ettlie and Stoll, 1990). Finally, as mentioned, QFD failures is measured by the reported number of failures $\left(F_{1}\right)$. In hindsight, this measure may be limited in that it is an absolute rather than relative measure of failures. It does not consider the overall number of QFD applications attempted and thus cannot be treated as a measure of failure rate. Further, information collected during the follow-up telephone interviews (for verifying the missing data values) indicated that just what constitutes a "failure" of QFD is a matter of opinion. There are degrees of success and failure, and even when QFD "fails," the companies learn a great deal from the experience.

Two aspects of our analysis help us to address these potential limitations. First; our results will indicate whether or not companies label QFD efforts as failures even though they gain significantly on the customer focus and process improvement dimensions; the analysis would show nonsignificant or positive effects for QFD-based customer focus and QFD-based process improvement on the incidence of QFD failures. Second, earlier analyses included the direct effects of both size and benchmarking on the incidence of failures. Including the direct effect of the size of the organization on QFD failures should help control for a potential difference between the incidence of failures and failure rate. Other things equal, one would expect more QFD applications in larger organizations. However, both effects were nil. In the end, QFD failures is still a subjective estimate on the part of our key informants.

Our model was estimated using partial least squares (PLS). PLS and covariance structure analysis (using LISREL7) are two recommended methods for estimating structural models of this type where multiple indicators are used (Fornell, 1987). PLS aims to account for variances at the observed (measurement) level, while LISREL aims to account for observed covariances. One implication is that PLS is more appropriate when the model in question is more exploratory, the theory is weaker, and the focus is on prediction rather than the testing of alternative theories. Thus PLS is more consistent with both the exploratory nature of our model and its emphasis on explaining QFD failures. Finally, because PLS is less restrictive in its assumptions regarding data, it is recommended for smaller samples where categorical measures are included (Fornell, 1987). 
Having complete data for our sample of 33 firms allows us to use Tukey's jackknifing method to assess the precision of each parameter estimate in the model (Fornell and Barclay, 1993). There was one missing case value for our benchmarking measure, and this was filled in using the group average. Information on revenues and the number of full-time employees was available for 23 and 30 of the 33 firms respectively. Again, these values were filled in using the group averages. Even though there are no statistical grounds on which to generalize beyond the 33 cases studied here, the jackknife results are used to examine the reliability of the measurement loadings and path coefficients.

Several other model estimations were used to examine the sensitivity of our results to the assumptions and procedures used to both collect and analyze the data. In addition to our main model, we estimated the model using the larger sample of 45 firms (the original 46 less the one outlier) without incorporating missing case values for benchmarking, revenues, or number of employees. We then estimated the model for our core 33 firms, again without filling in any missing case values. To explore a possible bias due to the use of follow-up phone interviews to fill in missing information on QFD failures, we also estimated the model using our core sample of 33 firms without filling in any missing case values and excluding the added failure information. Finally, because two firms in the survey may be considered outliers in that they reported only two and four employees, respectively, compared to 500 for the next largest firm, we estimated the model excluding these firms $(n=31)$.

\subsection{Results}

The estimation output is presented in Figure 1. For those constructs with single indicators, the measurement loadings are equal to 1.000. In those cases where multiple measures are used, the loadings are generally large and positive and exceed the path coefficients which supports the measurement model. The RMS (root mean square) residual covariance among the measurement variables is .101 , which represents 44 percent of the RMS measurement variable covariance. The RMS residual covariance among the latent variables is only .025 ( 9 percent of the available latent variable covariance). This supports our conceptual model and the specification of relationships among the latent variables. The model explains 12 percent of the variance in failures, 42 percent of the variance in process improvement, and 5 percent of the variance in customer focus.

QFD-based customer focus and process improvement both result in a lower incidence of failures (coefficients of -.285 and -.178 , respectively, and jackknife standard errors of .033 and .025 ). This is consistent with the notion that the incidence of QFD failures is affected directly by the degree to which QFD accomplishes its two primary objectives. These results add credence to our failure measure, in that QFD projects do not appear to be labeled as subjective failures even though they provide significant benefits. 


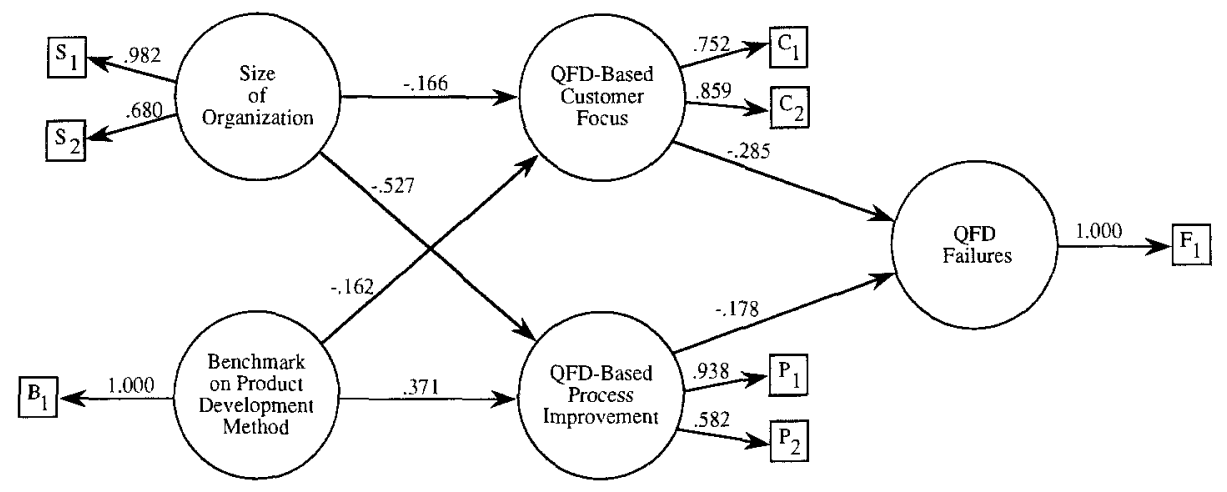

Figure 1. Conceptual Model and Results

While benchmarking has a sizable positive effect on process improvement (.371, standard error of .024), it has a reliable negative effect on customer focus $(-.162$, standard error of .027). These results support the proposed tradeoff whereby focusing on competitors comes at the expense of focusing on customers; benchmarking on the product-development methods of one's competitors, peers, or models actually reduced customer focus among the firms studied here. Thus benchmarking has near offsetting effects on QFD failures, a positive effect via customer focus $(-.162 *-.285=.046)$ and a negative effect via process improvement $(.371 *-.178=-.066)$.

Larger organizations gained less customer focus using QFD than did smaller organizations (coefficient of -.166 , standard error of .022). There is also a large negative effect of size on QFD-based process improvement (coefficient of - .527, standard error of .070). Thus QFD provided greater relative customer focus and process improvement benefits among our smaller firms. As described earlier, the negative effects of size suggest that QFD is more constrained in larger organizations. Another possible explanation is that, while QFD may be the primary method by which a smaller firm improves total quality, it is one among many methods or processes being adopted by larger firms and thus has a smaller relative impact. In the U.S., continuous (process) improvement efforts also tend to be housed more uniquely in the engineering departments of larger firms (Cole, 1990). This may make the effect of more cross-functional process-improvement efforts less effective.

Recall that we also estimated the model using (1) the larger sample of forty-five firms without incorporating missing case values, (2) the same sample of thirtythree firms without incorporating missing case values, (3) the same sample of thirty-three firms without incorporating missing case values and excluding the thirteen cases of failure data collected using follow-up phone interviews, and (4) a smaller sample of thirty-one firms that excludes the firms that reported having only two and four employees. Consistent with the results in Figure 1, the measurement loadings were large and positive in each case and exceeded the path 
coefficients. The direction and size of the path coefficients was very similar across the models. The only exception was for missing case model 1 , in which size had no effect on customer focus. Overall, our findings are not particularly sensitive to the assumptions and procedures used in the data collection and analysis.

\section{Discussion}

Quality function deployment is a quality-improvement method designed to both increase customer focus and facilitate process improvement. We examined thirtythree firms' experience in implementing this method. Our results illustrate the tension that exists between focusing on customers and focusing on other firms' practices. The path one takes when implementing quality improvement affects the benefits received. Firms that benchmark on other firms' development practices were more likely to improve their own operations using QFD. Yet benchmarking decreased QFD-based customer focus in these same firms. This suggests that there is some primary goal, bias, or limited capacity in a product-development team's focus of attention. The more the team focuses on what competitors are doing, the less focused it becomes on end-user needs and wants. Future research should be directed at understanding the basis of this effect. One possibility is that smaller firms suffer more from limited capacity while large, established firms suffer more from a prevailing organizational perspective - such as quality is free.

Another important finding is that smaller firms gain both greater customer focus and process improvement from using QFD than do larger firms. Larger firms are more likely to suffer from the existence of functional silos and a rigid organizational structure. Again, future research should explore this relationship to better understand the reasons why larger firms are hampered in their quality-improvement efforts. Finally, our results reinforce the central role played by customer input in a firm's quality-improvement efforts.

Naturally, while we examined a diverse sample of firms and their experience with actual QFD applications, there are limitations to our study. Our sample is relatively small and was not randomly selected from the population of QFD users. Limiting the sample to ASI symposium participants may introduce a bias. It would also be useful to have had a wider range of measures for our customer focus and process improvement constructs given their complexity and importance. As noted, our measure of QFD failures may not reflect failure rate. We examined perceived rather than objectively measured benefits of QFD and self-reported QFD failures. At the same time, our analysis checked for the potential effect of firm size on QFD failures, and our results suggest that these limitations do not have any overriding effect on our findings. Finally, our key respondents may not accurately portray the full range of experiences of the product-development teams. Yet these respondents were extremely knowledgeable of their firms' QFD efforts, as many of our follow-up data-collection efforts indicated. The respondents appeared to have a deep understanding of the subtle definitions of success 
and failure of product-development methods in their companies. In any event, understanding perceptions of failure or success is critical as it is these perceptions that often drive behavior.

\section{Notes}

The authors gratefully acknowledge the support of the Office of Manufacturing Management Research, the National Quality Research Center, and the Manufacturing Forum at the University of Michigan's School of Business Administration as well as the kind assistance of the American Supplier Institute for making this study possible.

\section{References}

Andrews, D. F., P. J. Bickel, F. R. Hampel, P. J. Huber, W. H. Rogers, and J. W. Tukey. (1972). Robust Estimation of Location. Princeton: Princeton University Press.

Camp, Robert C. (1989). Benchmarking. Milwaukee: Quality Press.

Cole, Robert. (1990). "U.S. Quality Improvement in the Automobile Industry: Close but No Cigar," California Management Review 32 (Summer), 71-85.

Crosby, Philip B. (1979). Quality Is Free. New York: Penguin Books.

Damanpour, Fariborz. (1991). "Organizational Innovation: A Meta-Analysis of Effects of Determinants and Moderators," Academy of Management Journal 34 (September), 555-590.

Deshpande, Rohit, and Gerald Zaltman. (1981). "Factors Affecting the Use of Market Research Information: A Path Analysis," Journal of Marketing Research 19 (February), 14-31.

Ettlie, John E., and Henry W. Stoll. (1990). Managing the Design-Manufacturing Process. New York: McGraw-Hill.

Fiske, Susan T., and S. E. Taylor. (1984). Social Cognition. Reading, MA: Addison-Wesley.

Fornell, Claes. (1987). "A Second Generation of Multivariate Analysis: Classification of Methods and Implications for Marketing Research." In Michael J. Houston (ed.), Review of Marketing 1987. Chicago: American Marketing Association.

Fornell, Claes and Donald W. Barclay. (1993). "Jackknifing in PLS." Research Note: The University of Michigan, School of Business Administration, Ann Arbor, MI 48109.

Griffin, Abbie. (1989). "Functionally Integrated New Product Development." Unpublished Ph.D. thesis, Sloan School of Management, M.I.T. . (1992). "Evaluating QFD's Use in US Firms as a Process for Developing Products," Journal of Product Innovation Management 9(2), 171-187.

Griffin, Abbie and John R. Hauser. (1992). "Patterns of Communication Among Marketing, Engineering and Manufacturing: A Comparison Between Two New Product Teams," Management Science 38(3), 360-373.

(1993). "The Voice of the Customer," Marketing Science 12(1), 1-27.

Hauser, John R., and Don Clausing. (1988). "The House of Quality," Harvard Business Review, Reprint No. 88307.

Port, Otis, and Geoffrey Smith. (1992). "Beg, Borrow - and Benchmark," Business Week, November $30.74-75$. 